\title{
Investigating the histopathological effects of saffron petal (Crocus Sativus L.) hydroalcoholic extract on kidney and liver functional parameters in rats
}

\author{
Monireh Azizi $^{1 \oplus}$, Mohammad Reza Hafezi Ahmadi' ${ }^{2}$, Mojtaba Mohamadpour $^{3 \oplus}$, Ahmad Daemi ${ }^{3 \oplus}$, \\ Sirous Asadi ${ }^{3}$, Ehsan Shirzadpour ${ }^{4 \oplus}$, Mansour Amraei ${ }^{5,6, *(0)}$
}

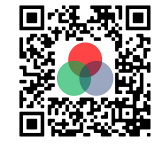

Use your smartphone to scan this QR code and download this article

${ }^{1}$ Department of Anatomy, Faculty of Medicine, Ilam University of Medical Sciences, Ilam, Iran

${ }^{2}$ Department of Pathobiology, Faculty of Medicine, Ilam University of Medical Sciences, Ilam, Iran

${ }^{3}$ Student Research committee, Ilam University of Medical Sciences, Ilam, Iran

${ }^{4}$ Department of Biochemistry, Faculty of Medicine, Ilam University of Medical Sciences, Ilam, Iran

${ }^{5}$ Biotechnology and Medicinal Plants Research Center, Ilam University of Medical Sciences, Ilam, Iran

${ }^{6}$ Department of Physiology, Faculty of Medicine, Ilam University of Medical Sciences, Ilam, Iran

\section{Correspondence}

Mansour Amraei, Biotechnology and Medicinal Plants Research Center, Ilam University of Medical Sciences, Ilam, Iran

Department of Physiology, Faculty of Medicine, Ilam University of Medical Sciences, Ilam, Iran

Email: amraei.mansour@yahoo.com History

- Received: Oct 01, 2019

- Accepted: Feb 04, 2020

- Published: Apr 30, 2020

DOI : 10.15419/bmrat.v7i4.600

\section{Check for updates}

\section{Copyright}

(c) Biomedpress. This is an openaccess article distributed under the terms of the Creative Commons Attribution 4.0 International license.

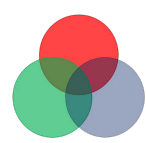

\begin{abstract}
Background: Saffron is one of the main food products in Iran, and its countless medicinal properties have been used widely in traditional medicine. Many studies conducted and reported in the literature have shown that plant-based medicines, such as chemical drugs, may also have unexpected side effects. Thus, the present study aimed to investigate the histopathological effects of the hydroalcoholic extract of the saffron petal (HAESP) on the liver and kidney, particularly on their functional parameters in rats. Methods: The first group (control) received ordinary daily dietary regime. In addition, Groups 2, 3 and 4 were fed an ordinary dietary regimen along with HAESP (at 200,400 , or $600 \mathrm{mg} / \mathrm{kg} /$ day). The treatment was continued on a daily basis for four weeks, and upon the termination of the treatment, blood samples were collected from all the rats. Then, tissue samples were prepared from the animals' kidney and liver for histological studies. Results: The histological results are indicators of notable changes in the glomerulus, tubules, and interstitial tissue of the kidney cross-sections for the groups receiving HAESP. In the central vein region and the port space of the liver cross-sections, dose-dependent changes were found in the groups that had received HAESP. The study results also suggest a considerable statistical increase in the mean levels of renal enzymes and hepatic enzymes in different groups receiving HAESP. Conclusion: The findings of the present study reflect the idea that the saffron petal hydroalcoholic extract can be effective even on renal and hepatic cells, and even in non-poisonous dosages. Therefore, care should be exercised in using the extract for its potentially therapeutic effects.

Key words: Saffron, Kidney, Liver, Histopathology, Wistar rat
\end{abstract}

\section{INTRODUCTION}

Access to and use of industrial drugs and substances have increased, along with the progress in science and industrialization of communities. In addition, according to the fact that some drugs have numerous side effects, researchers have been searching for more effective drugs with lower side effects and more plantbased nature $^{1}$. In Iranian traditional medicine, the use of medicinal herbs for treating diseases has been emphasized, and the application of medicinal plants has recently drawn great attention due to their ease of access, reduced side effects, and reasonable price as a competent substitute for industrial drugs ${ }^{2}$.

Saffron is one of the medicinal plants that has been used for a long time in Iran. Saffron (Crocus Sativus L.), known as the most expensive spice in the world, is a small flower-bearing plant that belongs to the Iridaceous family ${ }^{3}$. This perennial plant is cultivated in Azerbaijan, France, Greece, India, Iran, Italy, Spain, China, Morocco, Turkey, Egypt, and Mexico ${ }^{4}$. The agricultural cultivation of saffron dates back to 3500 years ago. The plant can grow up to 12 inches in height, and it bears three to four petals of which each has three red stigmas ${ }^{5,6}$. The dried stigma of saffron is used as a condiment for the flavor it produces as well as for food coloring; the petals are usually thrown away $^{7}$.

Saffron contains more than 150 chemical ingredients, amongst which three main elements, namely crocin (color), picrocrocin (flavor), and safranal (odor), are responsible for its pharmacological effects ${ }^{8}$. Picrocrocin, a monoterpene glycoside, is the major flavor component of saffron. Safranal, a monoterpene aldehyde, is one of the major smell and odor sources of saffron. Crocin is responsible for the coloring effect of saffron ${ }^{9-11}$. Crocin, a water-soluble carotenoid, is the most abundant antioxidant among the active saffron components ${ }^{10,11}$. Crocin and safranal have various pharmaceutical activities, such as antioxidant, anti-carcinogenic, anti-cerebral, -renal, -cardiac, musculoskeletal ischemia, blood pressure reduction, 
blood sugar reduction, anti-hyperlipidemic, sexual performance improvement, gene protection, antitoxic, memory boosting, antidepressant, morphine withdrawal syndrome inhibition, and diazinon antibiotic properties 121314151617 . Studies have shown that saffron is an appetizer, tranquilizer, food digestion facilitator, expectorant, and emmenagogue ${ }^{18}$. Moreover, it can be used to treat cough, pertussis, asthma, gastric disorders, pyrosis, maldigestion, hepatic and gall bladder disorders, nose and throat mucosal inflammation, insomnia, arterial hardening (atherosclerosis), hernia, Alzheimer's, shock, hemoptysis, pain, alopecia, dry skin, depression and cognitive disorders, and urinary infections ${ }^{18} 19$.

Similar to industrial drugs, medical plants might cause irreparable tissue damage due to unwanted side effects $^{20}$. Therefore, the study of side effects of medicinal plants can help in the identification and recognition of the safety specifications of these drugs in humans, as well as understanding the specialization of their applications. Although many studies have reported on the useful effects of saffron in treating clinical disorders and diseases, there is a scarcity of information regarding its toxic profiles. In the studies performed in this regard, crocin was not found to cause considerable damage to the body organs, and no death was scored in rats treated with high dosages of crocin administered via intraperitoneal injection (3 $\mathrm{g} / \mathrm{kg}$ ) during a two-day treatment period ${ }^{21}$. However, administering saffron in dosages ranging between 1.2 $\mathrm{g}$ and $2 \mathrm{~g}$ to human subjects has been found to cause nausea, vomiting, diarrhea, and hemorrhage ${ }^{22}$. In high doses (200 mg/day and $400 \mathrm{mg} /$ day), saffron can alter some hematological and biochemical parameters. However, these changes are in a natural range and not clinically significant ${ }^{23}$. Thus, the determination of the drug usage amount, as well, is of great importance for understanding the irreparable side effects resulting from high doses. Therefore, it is necessary to perform various investigations in different dosages of drug usage, with the objective of recognizing their harmful effects on various tissues so that the exact and non-toxic use rate of the drug can be specified.

Although saffron is being widely used in some countries, it is necessary to carry out extensive scientific research in line with the identification of the side effects and determination of the use levels of this plant. On the other hand, a large amount of saffron petal is thrown away yearly as agricultural waste, despite the substantial evidence indicating the existence of ingredients with different pharmacological effects in the saffron petal. Hence, the research study herein was conducted with the objective of investigating the histopathological effects of saffron petal hydroalcoholic extract on the functional parameters of the kidney and liver in rats.

\section{MATERIALS - METHODS}

\section{Plant and extract preparation}

The saffron petals studied in the present study were procured from the saffron farms around Mashhad (Iran). To prepare the extract, at first, a certain amount of saffron petal was measured and ground. Then, the petals were mixed in ethanol $80 \%$ (for a 1:20 ratio) and kept in ambient temperature, away from any sunlight for 72 hours. After the elapse of the aforementioned time, the solution was filtered and centrifuged (BMA k1500, HAWAROMA, Germany) at $2500 \mathrm{rpm}$ for $10 \mathrm{~min}$, and the solution part was carefully separated. Then, the additional solvent was removed in a device in a vacuum (RV10 CONTROL V, IKA, Germany) at $40^{\circ} \mathrm{C}$, and the rest of the solution was transferred to a volumetric flask into several Petri dishes that were subsequently placed inside a $30^{\circ} \mathrm{C}$ oven (DZF 6020, ZENITH LAB, China). After $24 \mathrm{~h}$, the dried plates were scraped using a spatula and were then kept in the refrigerator for later experiments.

\section{Determination of the lethal dosage (LD)}

To determine the lethal dosage of saffron petal hydroalcoholic extract, 64 mature male Wistar rats were assigned to eight groups (with $n=8$ per group). The first group (control) was administered with $2 \mathrm{cc}$ normal saline, and the other groups were gavage fed on saffron petal hydroalcoholic extract at 50, 100, 200, $400,800,1600$, or $3200 \mathrm{mg} / \mathrm{kg}$ dosages. Then, the apparent behaviors, physical health, nervous signs, feed consumption rate, urine, and solid waste excretion statuses, as well as mortality rates of the animals, were investigated for the different groups for a period of 24 h. Next, computer techniques were employed to calculate $\mathrm{LD}_{50}$ and $\mathrm{LD}_{100}$ dosages 24252627 .

\section{Animal procurement and maintenance}

This study was conducted on mature male Wistar rats between $225 \pm 25 \mathrm{~g}$ in weight, and ten weeks old; the rats had been procured from the center for raising laboratory animals of Ilam Medical Sciences University. The experimental animals were kept in a room at a temperature of $23 \pm 2^{\circ} \mathrm{C}$ and in a 12:12 dark-light cycle inside special cages made of polycarbonate. The relative humidity of the room was set at $60 \pm 5 \%$. All of the rats were allowed to have free access to water and food during the experiment; they were nourished 
on special compressed food and also provided with urban tap water. Before the experiment commencement, the animals were allowed to get accustomed to the environment and the conditions for two weeks. In addition, during the work, all of the articles and codes of ethics stipulated for animal research procedures, including education and treatment, by Iran's Ministry of Healthcare were taken in account.

\section{Experimental design}

To undertake the experiment, 28 mature male Wistar rats were randomly assigned to 4 groups (with $\mathrm{n}$ $=7$ per group). The first group (control) was fed an ordinary daily dietary regimen. The second, third, and fourth groups (experimental groups 1,2, and 3) were also given an ordinary daily dietary regime along with saffron petal hydroalcoholic extract of dosages equal to 200, 400, or $600 \mathrm{mg} / \mathrm{kg}$.BW, respectively. At the end of the experiment, bypassing $24 \mathrm{~h}$ from the last treatment, blood samples were collected from all the rats, and their livers and kidneys were isolated for histopathological examinations following putting the animals under anesthesia using ether.

\section{Measuring hepatic and renal enzyme levels}

Before the initiation of the treatment, and after the termination of the treatment period, the animals were kept in fasting status for $12 \mathrm{~h}$. Then, blood samples were recollected from all the rats in order to measure the levels of the intended enzymes. The samples were collected once at the first day of treatment and a second time at the end of week four. The collected blood samples were poured in serum separation tubes for $20 \mathrm{~min}$ and kept at laboratory temperature to become coagulated. Next, they were centrifuged at $25000 \mathrm{rpm}$ for $15 \mathrm{~min}$, and serum from the blood samples were collected. The prepared serum samples were used to measure various biochemical factors of the liver performance index, including alkaline phosphatase (ALP), aspartate aminotransferase (AST), alanine aminotransferase (ALT), and gammaglutamyl transferase (GGT), as well as renal enzymes, including blood urea nitrogen (BUN), and creatinine, via the biological-chemical measurement kits (Pars Azmun Co. Tehran, Iran), according to the chromatographic methods in the Auto-Analyzer Device (Analyzer A15, BioSystem, Spain).

\section{Histological examinations}

After the termination of the experiment and collection of blood samples from all rats, the animals were anesthetized using chloroform, and their livers and kidneys were separated for histological investigations. After macroscopic inspections, these organs were fixed in a $10 \%$ buffered formalin solution. After performing tissue passage, paraffinic blocks were prepared from the tissue samples, and sections ( $5 \mu \mathrm{m}$ in thickness) were made using a Microtome Device (YD-335A, YIDI, China). The sections were then deparaffinized by xylol for 3 times and rehydrated by different degrees of Ethanol (100, 95 and $80 \%$, every 3 times), and were then washed by deionized water (3 times). After that, Hematoxylin-Eosin (H\&E) staining was conducted according to the manual protocol from the Baylor College of Medicine (the H\&E staining is shown as supplementary data). The slides were dehydrated by increasing the degree of ethanol (95 and 100\%), followed by 3 times clearing by xylol and finally coverslipped using permount. In the end, a light microscope was used for preparing tissue images.

In the investigation of the kidney tissue damages, the cortex, external medulla, and internal medulla were separately examined under a light microscope. The cortex was inspected for Bowman space enlargement, cell necrosis and sloughing into the tubule lumen. In addition, the external medulla was examined for tubular damages, vascular congestion, and formation of proteinaceous casts inside the tubules. Finally, the internal medulla was assessed for the formation of proteinaceous casts inside the tubules and for vascular congestion.

Histopathological investigations of the liver crosssections, as well, were carried out using a semiquantitative scale and in a double-blind manner in order to evaluate the damages. The observed histopathological changes were categorized based on the intensity of lesion, in contrast to a normal state, as mild damage (mild hydropic degeneration, nonproliferation of Kupffer cells, and absence of necrosis), intermediate damage (intermediate hydropic degeneration, Kupffer cells proliferation, and absence of necrosis or trivial necrosis), and severe damage (intensive hydropic degeneration, Kupffer cells proliferation, and necrosis).

\section{Data analysis}

To statistically analyze the data, SPSS Software version 16 was used. The obtained quantitative data were presented as Mean \pm SEM. To compare the inter-group means, a one-way variance analysis and Tukey followup test were employed. The significance level was set at $\mathrm{P}<0.05$ for all tests. 


\section{Ethical considerations}

The present study was approved with a certification letter for medical research that was issued by the ethics committee of Ilam University of Medical Sciences, with the code number of (IR.MEDILAM.REC.1397.033).

\section{RESULTS}

\section{Acute phase}

The results obtained from the study during the stage of determining the acute toxicity of the saffron petal hydroalcoholic extract (HAESP) indicated that $\mathrm{LD}_{50}$ and $\mathrm{LD}_{100}$ of the saffron petal hydroalcoholic extract are about $670 \mathrm{mg} / \mathrm{kg}$ and $1463 \mathrm{mg} / \mathrm{kg}$, respectively (Table 1).

After determining the $\mathrm{LD}_{50}$ rate of the saffron petal hydroalcoholic extract (acute phase) in the present study, the effects of long-term treatment (chronic phase) by non-toxic dosages $(30 \%, 60 \%$, and $90 \%$ of $\mathrm{LD}_{50}$ dosage) of this extract, i.e. 200, 400, and 600 $\mathrm{mg} / \mathrm{kg}$ dosages, were investigated for their effects on renal and hepatic tissues, as well as renal/hepatic performance parameters in rats.

\section{Chronic phase}

\section{Histopathological effects}

Figure 1 illustrates the Hematoxylin-Eosin (H\&E)stained histopathological images of the kidney crosssections among the various study groups. No glomerular damage was evidenced in any of the groups. Furthermore, the tubules were found with no problem in terms of the tissue, and no inflammation was observed in them. The interstitial tissue was also found with normal structure in all of the studied groups. In summary, no observable histological differences were found in kidney tissues between the control group and the groups receiving various dosages of saffron petal hydroalcoholic extracts (Figure 1).

The histopathological images of the central vein region in the liver cross-sections are shown in Figure 2 for the various groups. The analysis of the liver cross-sections stained with H\&E suggests normal tissue structure in the control group, and no observed sign of inflammation or degeneration in the central vein region of this group. However, the tissue changes associated with the groups receiving HAESP at various dosages were clearly visible. For instance, in the hepatic tissue of the animals which received saffron petal hydroalcoholic extracts, the reversible hydropic changes were found undergoing a linear increase with the elevation of the dosage in such a way that these changes were found mini-mild in the group that had received $200 \mathrm{mg} / \mathrm{kg}$ of HAESP, mild in the group that had received $400 \mathrm{mg} / \mathrm{kg}$ of HAESP, and mild to intermediate in the group that had received $600 \mathrm{mg} / \mathrm{kg}$ of HAESP (Figure 2).

Figure 3 demonstrates the port space of the liver cross-sections. The analyses showed as well that the control group had a normal tissue structure, and no sign of inflammation or degeneration was tracked in the port space (Control). Nevertheless, tissue changes were evidenced in a dosage-dependent manner in groups that had received various dosages of HAESP in such a way that focal confluent necrosis was observable in hepatic parenchyma (Exp1-A), and portal inflammation was also evident (Exp1-B) in the first experimental group that had been treated by 200 $\mathrm{mg} / \mathrm{kg}$ of the extract. As for the second experimental group (administered with $400 \mathrm{mg} / \mathrm{kg}$ of the extract), more cells were found with focal confluent necrosis (Exp2). Finally, severe confluent necrosis (Exp3-A) along with inflammatory cells were seen in the portal space (Exp3-B); this was completely evident in the third experimental group that had been treated with $600 \mathrm{mg} / \mathrm{kg}$ of HAESP (Figure 3).

Before the initiation of the study and at the end of the treatment, the mean levels of the renal enzymes (BUN and creatinine) and hepatic enzymes (ALP, AST, ALT, and GGT) were measured for the studied groups. The results of renal enzyme measurements- before and after the experiment- are summarized in Table 2. As it was observed, the comparison of the BUN and creatinine enzyme levels, before and after the study, indicated no significant differences in the control group $(P>0.05)$. However, the serum levels of these enzymes were found to have significant increase at the end of the intervention as compared to the beginning of the study in the groups administered with HAESP $(\mathrm{P} \leq 0.05)$. In addition, findings of this study indicated that the increase in HAESP dosage brings about increased serum levels of the renal enzymes, as well, in such a way that the highest serum level elevation of these enzymes was respectively documented for the groups that had received higher dosages of HAESP. For example, the BUN enzyme levels were $60.14 \pm$ $5.01,62.14 \pm 5.39$, and $85.28 \pm 3.56$, for dosages of 200,400 , and $600 \mathrm{mg} / \mathrm{kg}$, respectively; this is suggestive of a dosage-dependent effect of this medicinal plant-based extract (Table 2).

Figure 4 presents the results related to the comparison of the serum concentrations of the renal enzymes in the groups that had received HAESP with those of the control group after the termination of the examination. Accordingly, as can be seen, there is a significant difference between groups that had been treated 


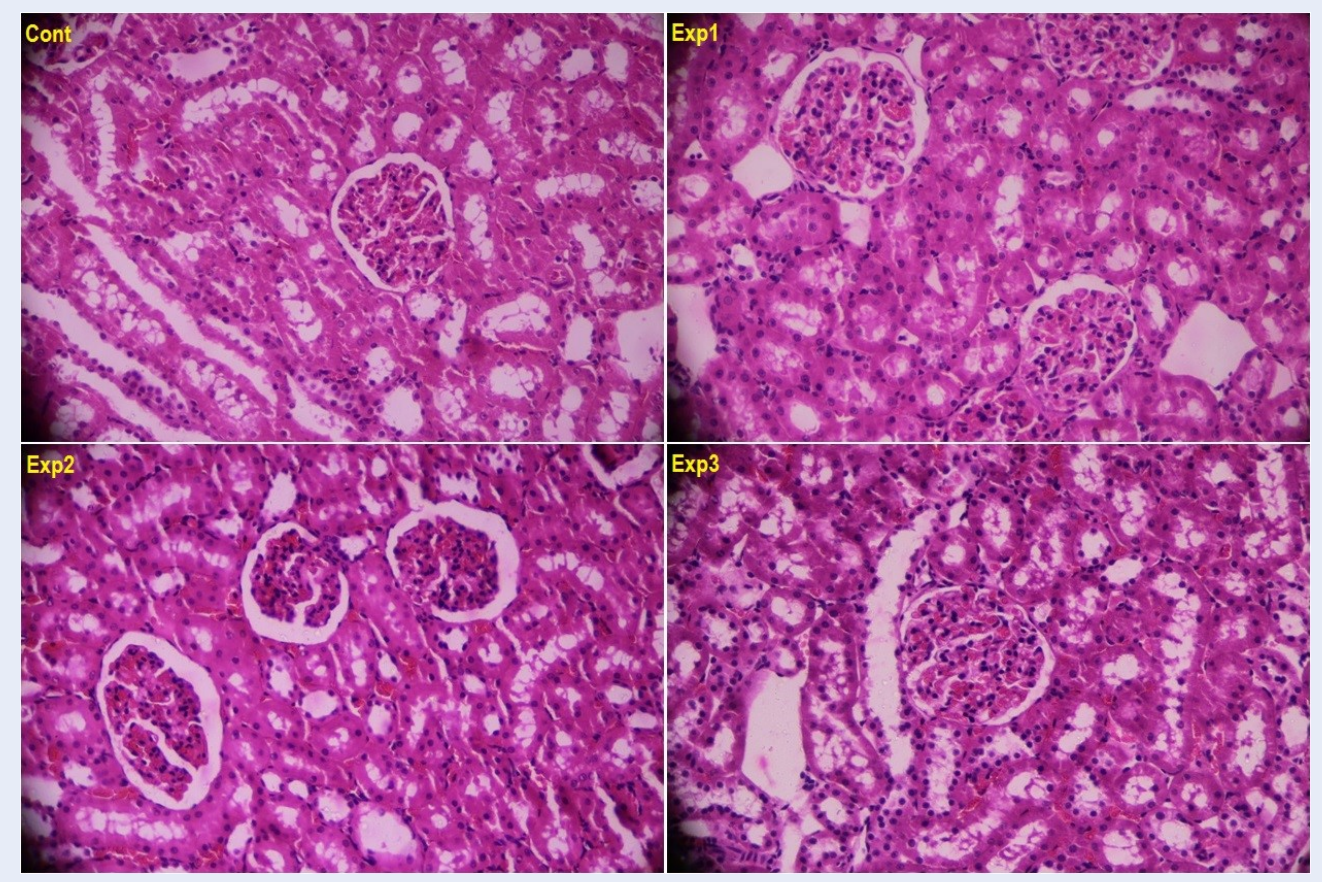

Figure 1: Histopathological images of Kidneys' cross-sections stained by Hematoxylin-Eosin (H\&E) in thevarious experimental groups. Cont: control group, Exp1: 200 mg/kg HAESP, Exp2: 400 mg/kg HAESP; Exp3: 600 $\mathrm{mg} / \mathrm{kg} \mathrm{HAESP}$.

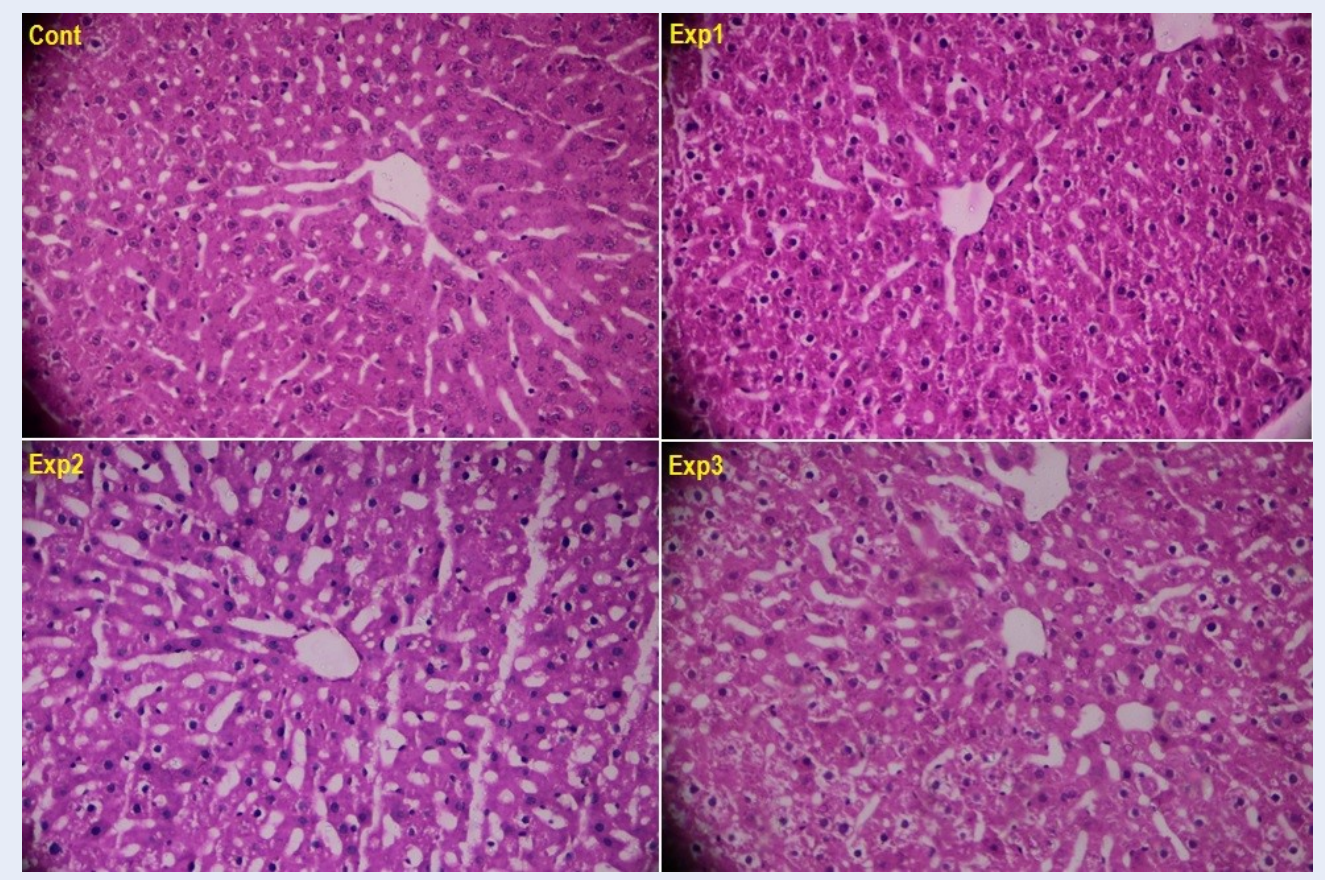

Figure 2: Histopathological images of the central vein region of liver cross-sections stained by Hematoxylin-Eosin (H\& E) in the various experimental groups. Cont: control group, Exp1: 200mg/kg HAESP, Exp2: $400 \mathrm{mg} / \mathrm{kg} \mathrm{HAESP}$; Exp3: $600 \mathrm{mg} / \mathrm{kg}$ HAESP. 
Table 1: Comparison of the toxicity rates of various HAESP dosages on rats in acute phase

\begin{tabular}{llc}
\hline HAESP Dose $(\mathrm{mg} / \mathrm{kg})$ & Symptoms & Death (\%) \\
\hline Normal saline & Normal & 0 \\
50 & Normal & 0 \\
100 & Stressed rat & 0 \\
200 & Piloerection, Stressed rat, Immobilization & 0 \\
400 & Tremor, Labored breathing, Death & 25 \\
800 & Tremor, Labored breathing, Death & 75 \\
1600 & Death & 100 \\
3200 & Death & 100 \\
\hline
\end{tabular}

Table 2: Comparison of the serum concentrations of renal enzymes in each group before and after being treated by HAESP

\begin{tabular}{llcccc}
\hline \hline Kidney enzymes & & $\begin{array}{c}\text { Control } \\
\text { group }\end{array}$ & $\begin{array}{c}\text { HAESP 200 } \\
\mathrm{mg} / \mathrm{kg} / \mathrm{day}\end{array}$ & $\begin{array}{c}\text { HAESP 400 } \\
\mathrm{mg} / \mathrm{kg} / \mathrm{day}\end{array}$ & $\begin{array}{c}\text { HAESP 600 } \\
\mathrm{mg} / \mathrm{kg} / \mathrm{day}\end{array}$ \\
\hline $\begin{array}{l}\text { Blood Urea } \\
\text { Nitrogen (mg/dL) }\end{array}$ & before the intervention & $52.14 \pm 6.98$ & $57.57 \pm 4.57$ & $56.57 \pm 8.50$ & $59.28 \pm 5.27$ \\
& after the intervention & $53.85 \pm 7.79$ & $60.14 \pm 5.01$ & $62.14 \pm 5.39$ & $85.28 \pm 3.56$ \\
& P-value & $\mathbf{0 . 2 7 4}$ & $\mathbf{0 . 0 9 1}$ & $\mathbf{0 . 0 3 4}$ & $\mathbf{0 . 0 0 0}$ \\
\hline $\begin{array}{l}\text { Creatinine } \\
(\mathrm{mg} / \mathrm{dL})\end{array}$ & before the intervention & $0.43 \pm 0.01$ & $0.42 \pm 0.05$ & $0.44 \pm 0.04$ & $0.44 \pm 0.02$ \\
& after the intervention & $0.44 \pm 0.01$ & $0.49 \pm 0.03$ & $0.58 \pm 0.04$ & $0.89 \pm 0.05$ \\
& P-value & $\mathbf{0 . 5 1 0}$ & $\mathbf{0 . 0 4 0}$ & $\mathbf{0 . 0 0 9}$ & $\mathbf{0 . 0 0 0}$ \\
\hline
\end{tabular}

Data are presented based on mean $\pm \mathrm{SD}$. The mean difference is significant at the 0.05 level.

Table 3: Comparison of the serum concentrations of hepatic enzymes in each group before and after being treated by HAESP

\begin{tabular}{|c|c|c|c|c|c|}
\hline Liver enzymes & & $\begin{array}{l}\text { Control } \\
\text { group }\end{array}$ & $\begin{array}{c}\text { HAESP } 200 \\
\mathrm{mg} / \mathrm{kg} / \text { day }\end{array}$ & $\begin{array}{l}\text { HAESP } 400 \\
\mathrm{mg} / \mathrm{kg} / \text { day }\end{array}$ & $\begin{array}{c}\text { HAESP } 600 \\
\mathrm{mg} / \mathrm{kg} / \text { day }\end{array}$ \\
\hline \multirow{3}{*}{$\begin{array}{l}\text { Alkaline } \\
\text { Phosphatase } \\
(\mathrm{mg} / \mathrm{dL})\end{array}$} & before the intervention & $\begin{array}{c}601.71 \pm \\
46.97\end{array}$ & $538.71 \pm 37.84$ & $\begin{array}{c}552.85 \pm \\
47.63\end{array}$ & $578.28 \pm 59.37$ \\
\hline & after the intervention & $\begin{array}{c}612.71 \pm \\
61.20\end{array}$ & $658.71 \pm 44.99$ & $\begin{array}{c}796.28 \pm \\
35.47\end{array}$ & $\begin{array}{c}1093.85 \pm \\
111.26\end{array}$ \\
\hline & P-value & 0.114 & 0.008 & 0.000 & 0.000 \\
\hline \multirow{3}{*}{$\begin{array}{l}\text { Alanine } \\
\text { Aminotransferase } \\
(\mathrm{mg} / \mathrm{dL})\end{array}$} & before the intervention & $48.00 \pm 2.23$ & $55.71 \pm 4.92$ & $56.00 \pm 4.69$ & $48.71 \pm 3.54$ \\
\hline & after the intervention & $50.42 \pm 4.07$ & $58.85 \pm 7.05$ & $87.00 \pm 8.38$ & $96.57 \pm 6.16$ \\
\hline & P-value & 0.317 & 0.311 & 0.008 & 0.000 \\
\hline \multirow{3}{*}{$\begin{array}{l}\text { Aspartate } \\
\text { Aminotransferase } \\
(\mathrm{mg} / \mathrm{dL})\end{array}$} & before the intervention & $84.28 \pm 11.88$ & $89.00 \pm 10.48$ & $93.14 \pm 9.28$ & $83.85 \pm 11.36$ \\
\hline & after the intervention & $87.71 \pm 11.59$ & $105.28 \pm 13.06$ & $\begin{array}{c}109.28 \pm \\
7.36\end{array}$ & $161.57 \pm 9.94$ \\
\hline & P-value & 0.273 & 0.041 & 0.014 & 0.000 \\
\hline \multirow{3}{*}{$\begin{array}{l}\text { Gamma-glut } \\
\text { Transferase } \\
(\mathrm{mg} / \mathrm{dL})\end{array}$} & before the intervention & $2.71 \pm 0.48$ & $2.92 \pm 0.51$ & $2.71 \pm 0.55$ & $2.57 \pm 0.50$ \\
\hline & after the intervention & $2.85 \pm 0.49$ & $3.22 \pm 0.37$ & $3.74 \pm 0.37$ & $4.47 \pm 0.53$ \\
\hline & $P$-value & 0.722 & 0.044 & 0.002 & 0.000 \\
\hline
\end{tabular}

Data are presented based on mean \pm SD. The mean difference is significant at the 0.05 level. 


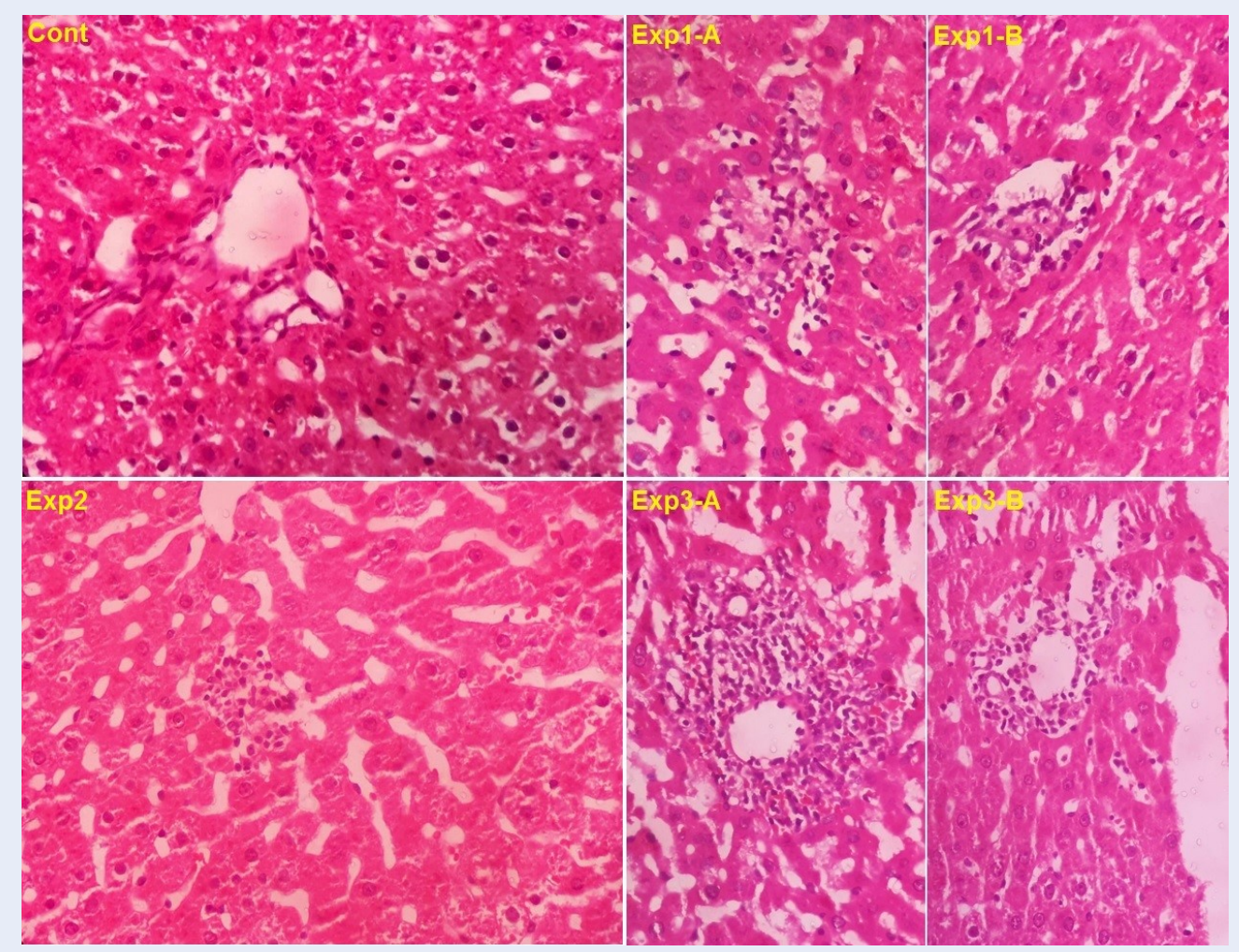

Figure 3: Histopathological images of portal space of livercross-sections of the rats stained by Hematoxylin-Eosin in the various experimental groups. Cont: control group, Exp1: $200 \mathrm{mg} / \mathrm{kg}$ HAESP, Exp2: $400 \mathrm{mg} / \mathrm{kg}$ HAESP; Exp3: $600 \mathrm{mg} / \mathrm{kg}$ HAESP.


Figure 4: Comparison of the serum concentrations of renal enzymes (BUN \& Creatinine) between the control group and 3 other groups that had received different dosages of HAESP $(200,400$ and $600 \mathrm{mg} / \mathrm{Kg}) .\left(^{*}: \mathrm{P}<\right.$ $\left.0.05,{ }^{* *}: P<0.01,{ }^{* * *}: P<0.001\right)$ 
with HAESP and the control group in terms of BUN and creatinine enzymes $(\mathrm{P}<0.001)$.

\section{Effects of liver enzymes}

Similar results were also observed concerning the hepatic enzymes (ALP, AST, ALT, and GGT) in that a significant difference was found among all the three groups that had received HAESP, in terms of the serum levels of these enzymes at the end of the study as compared with the beginning stage $(\mathrm{P}<0.05)$ (Table 3).

Additionally, the comparison of the amounts of ALP, AST, ALT, and GGT enzyme rates after the study between the control group and the groups that had received HAESP suggests there was a considerable increase in hepatic enzyme levels in the groups that had received HAESP as compared with the control group $(\mathrm{P}<0.001)$ (Figure 5).

Moreover, the dosage-dependent effect of HAESP was also demonstrated in this case in that the increase in HAESP dosage was found to exert a significant increase in the serum levels of the hepatic enzymes (Table 3 and Figure 5).

\section{DISCUSSION}

Saffron is a medicinal plant that has been widely applied, and possesses potential medicinal properties as well as a long past history of being used as a part of traditional medicine. Therefore, in order to develop its usage beyond a medication, it is necessary to evaluate its toxicity on the body organs. The present study was conducted with the objective of studying the effects of the saffron petal hydroalcoholic extract on parameters related to the kidney and liver of rats. The results obtained from the present study of acute toxicity determination of the saffron petal hydroalcoholic extract (HAESP) indicated that $\mathrm{LD}_{50}$ and $\mathrm{LD}_{100}$ dosages of the saffron petal hydroalcoholic extract were 670 $\mathrm{mg} / \mathrm{kg}$ and $1463 \mathrm{mg} / \mathrm{kg}$, respectively. Based on toxicity categorization, any substance with $\mathrm{LD}_{50}$ in a range between $1 \mathrm{~g} / \mathrm{kg}$ and $5 \mathrm{~g} / \mathrm{kg}$ can usually be recognized as less toxic, and any substance with an $\mathrm{LD}_{50}$ below $5 \mathrm{~g} / \mathrm{kg}$ is practically considered as nontoxic ${ }^{28} 29$. According to the study results, the $\mathrm{LD}_{50}$ computed for saffron petal administered to the rats was under the toxic limit and had even less toxic levels. Hence, saffron petal should be practically considered as being nontoxic in acute phase evaluation. The results of the study by Bahmani et al. are similar to our findings; in their study, the $\mathrm{LD}_{50}$ was found to be under $5 \mathrm{~g} / \mathrm{kg}$. The authors observed that saffron use at 500, 1000, or $2000 \mathrm{mg} / \mathrm{kg}$ could cause no death. However, the animals receiving saffron exhibited aggression and irritability, possibly due to the harmful nature of the majority of the essences ${ }^{30}$. In the study by Baba'ei et al., as well, no significant differences were found between the control group and saffron petal-treated groups in terms of the mean weight value increases during the entire treatment period. Since weight is of great importance with regard to an animal's general health, the authors concluded that the neutral effect of this byproduct on weight is reflective of its nontoxicity, and consequently, it has to be regarded as a considerable benefit for the use ${ }^{31}$. The results of the study by Karimi et al. are dissimilar to these findings for the reason that weight losses were scored for the animals that had received aqueous extract of saffron petal in spite of their unlimited access to water and food; they asserted that the extract injection could possibly cause anorexia in the animals ${ }^{32}$. The majority of the in-vivo studies on animals are suggestive of very low toxicity and/or even non-toxicity of saffron and its extracts $^{3334}$.

The biochemical and histopathological results of the present study signify toxic damages to the liver and kidney following the use of the hydroalcoholic extract of the saffron petal (HAESP). Liver damage level is often evaluated, mostly based on the levels of such hepatic enzymes as ALT, AST, ALP, and GGT. These enzymes are abundantly present in liver and necrosis or cell membrane damage, which causes the release of these enzymes in the blood $^{35}$.

The measurements of the levels of the aforementioned enzymes were used in evaluating the hepatic disorders, and the increase in the activity of the abovementioned enzymes is reflective of liver damage. The inflammatory disorders of hepatic cells result in the acute increase in their amounts ${ }^{36}$. The results of the present study indicate that saffron petal hydroalcoholic extract causes a significant increase in the mean serum levels of hepatic enzymes (ALP, AST, ALT, and GGT) in all three groups that received HAESP at the end of the study, in contrast to the beginning of the study, and as well as in comparison with the control group.

Moreover, for the toxic effects of saffron petal hydroalcoholic extract on the liver, we did not find many studies in the literature. Karimi et al. performed a study regarding the acute phase toxicity of saffron petals on rats using dosages of $1.2,2.4$, and $3.6 \mathrm{~g} / \mathrm{kg}$. accordingly, In the investigation of the biochemical factors of aqueous saffron extract, they observed that the use of saffron petal extract does not cause a significant change in ALP, TG, Chol, BUN, Cr, and CPK amounts; however, the amounts of AST, ALT, and 

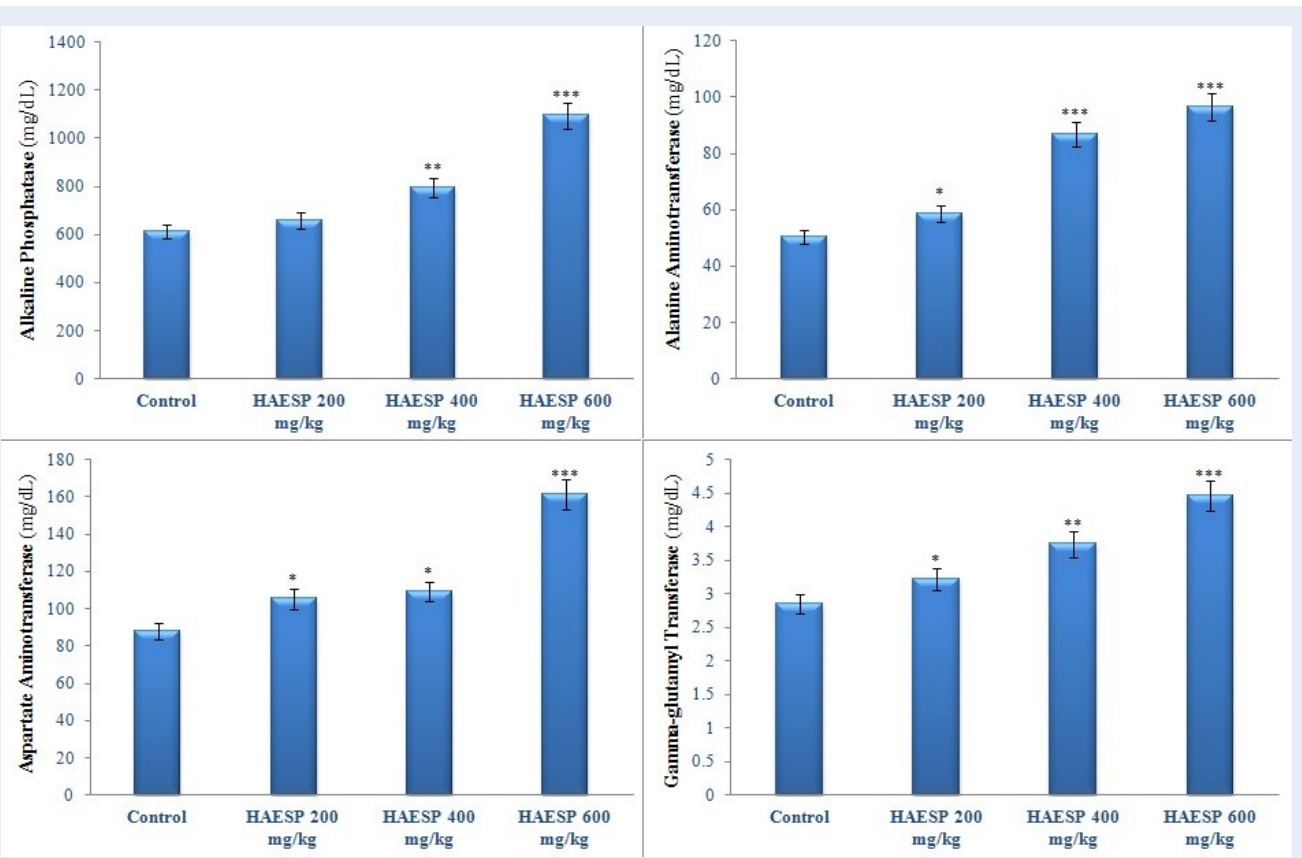

Figure 5: Comparison of the serum concentrations of hepatic enzymes between control group and the groups that had received various dosages of HAESP $(200,400$ and $600 \mathbf{~ m g} / \mathbf{K g}) .\left({ }^{*}: P<0.05,^{* *}: P<0.01\right.$, $\left.{ }^{* * *}: P<0.001\right)$

LDH enzymes increased, particularly in high dosages of the extract. On the other hand, tissue destruction was also observed in kidney, liver and lungs ${ }^{32}$; the results of the increase in the levels of AST and ALT enzymes and tissue damages of the kidney and liver are consistent with what has been found in the current research paper. In the study by Babaei et al., no significant change was found in ALT levels in the investigation of the effects of saffron petal extract at such dosages as $75,150,225$, and $450 \mathrm{mg} / \mathrm{kg}$, on some blood metabolites. On the other hand, it was found out that AST levels decreased in a dosage-dependent manner in contrast to the control group; this is suggestive of the non-destruction of hepatic cells and non-toxicity of the saffron petal hydroalcoholic extract in lower dosages ${ }^{31}$. Furthermore, this is not in compliance with what has been found in our study. In the study by Bahmani et al., as well, no change was observed in the histopathology evaluations and in the examination of the common hepatic intoxication markers, such as ALT, AST and bilirubin, following the use of saffron. They reported that saffron has no significant effect on the liver; however, it can cause kidney damages in the studied animals at higher dosages ${ }^{30}$. Based on other studies, dosages above $10 \mathrm{~g}$ saffron might be accompanied by side effects, including reduction in appetite, drowsiness, nausea, vomit- ing, uterine bleeding, hemorrhage, digestive tract mucosal bleeding, imbalance, and dizziness ${ }^{22}$.

The liver is the biggest gland and one of the most important parts of the body, which serves various functions, and is the main place for metabolism of materials. It can be damaged and inflicted with various diseases for it is constantly exposed to various chemical compounds, narcotics, and infections 3738 . In the present study, the histopathological studies are suggestive of severe hepatic tissue damage following the use of HAESP. The histopathological images of the central vein region in the liver cross-sections are indicative of dosage-dependent tissue changes in the groups that had received various dosages of HAESP. Furthermore, the images related to the portal space of liver cross-sections are reflective of portal inflammation and irreversible necrosis of the cells in the hepatic parenchyma in the group receiving $200 \mathrm{mg} / \mathrm{kg}$ of the extract. As well, more focal confluent necrosis was found in the group that received $400 \mathrm{mg} / \mathrm{kg}$ of the extract, and severe necrosis along with inflammatory cells was observed in the portal space of the group that received $600 \mathrm{mg} / \mathrm{kg}$ of the extract.

There are few findings with contradictory results regarding the toxic effects of the saffron petal on the liver. For instance, it was reported that the crocin 
separated from saffron could cause reversible accumulation of hepatic black pigments and acute hepatic damages resulting from this color change. Also, daily administration of $50 \mathrm{mg} / \mathrm{kg}$ saffron extract for eight days did not affect the hepatic performance. However, dosages higher than $100 \mathrm{mg} / \mathrm{kg}$ administered for two weeks was found to cause hepatic damage and accumulation of black pigments ${ }^{39}$. In another study, Hosseinzadeh et al. investigated the biochemical, hematological, and pathological scales in rats following their treatment with saffron extract ${ }^{21}$. The results of their study indicated that no change occurred in the common hepatic intoxication markers, such as levels of hepatic enzymes like ALT, AST, and bilirubin; this is contradictory to what has been observed in our study ${ }^{21}$.

In the present study, the results related to the measurement of the renal enzyme levels (creatinine and BUN), before and after the experiment, indicated that the serum levels of these enzymes had undergone considerable increases in the groups that received HAESP, compared to the control group, as justified in the scores at the end of the intervention comparing to the initial values. The histopathological findings of the kidney cross-sections indicated that there was no observable histological difference in terms of the renal tissues between the control group and the groups that had been treated by various dosages of saffron petal hydroalcoholic extract. The BUN and creatinine levels are considered as appropriate indicators of renal function. The increase in the BUN level in the treatment groups can lead to renal damages, and this effect has been confirmed based on the kidney histopathological results. In the study by Bahmani et al., the animals treated with saffron were found with an increase in blood urea nitrogen (BUN), and this is in accordance with the findings of the present study ${ }^{30}$. In the study by Hosseinzadeh et al., as well, the safranal-treated rats were found with blood urea nitrogen $(\mathrm{BUN})^{21}$; however, no significant difference was observed in terms of the serum creatinine level. Nevertheless, pathological changes were observed in the kidney ${ }^{22}$. The study by Karimi et al. indicated that the aqueous saffron petal extract causes no clearly visible and significant changes in the renal tissues and creatinine and BUN levels, which is not consistent with results from our present study ${ }^{32}$.

As it was discussed earlier, in according with the present study, several studies have shown that saffron petal has negative effects on the kidney and liver function, while no considerable effects have been reported for saffron petal on kidney and liver results in some other studies. One reason for such differences in the findings of various studies might be the studied sample volume, administration method, administration period, and applied dosage. The studies have shown that the study sample volume and type can affect the different results since changes in the detoxification systems, the differences in absorption, distribution, and excretion mechanisms in various kinds of animals, and the response to toxic substances might be different among species ${ }^{40}$. The application method is also another factor that may explain the contradictory results. The study by Hosseinzadeh et al., which treated the animals by oral and injective use of the saffron extract, indicated that safranal use in oral form in contrast to intraperitoneal injection could cause lower toxic effects ${ }^{21}$. Also, the reason for the high toxicity of safranal in intraperitoneal injection as compared to oral use might be due to the higher effect of the injective method and lower absorption in oral treatment ${ }^{21}$. In addition, the applied dosage and the study period can also largely account for the observed differences. In the present study, we used three non-toxic dosages, namely $30 \%, 60 \%$, and $90 \%$ of the $\mathrm{LD}_{50}$ dosage, of this extract, i.e., 200, 400, and $600 \mathrm{mg} / \mathrm{kg}$. However, the damages of these dosages, especially to the hepatic tissue, and their effects on the increase of the kidney and liver functional parameter levels were still observable in the long run. Parallel to the present study, many of the studies confirmed the dosage-dependent effect of saffron extract and showed that saffron extract is devoid of any side effects in lower dosages but causes serious damage to renal and hepatic tissues and increase in the related enzymes, particularly at the higher dosages ${ }^{30} 3233$. Therefore, the use of higher dosages of saffron should be avoided.

\section{CONCLUSION}

The present study indicated that there is a possibility of the emergence of hepatic and renal damages in acute phase prescription of saffron petal hydroalcoholic extract. The prescription of the saffron petal hydroalcoholic extract can significantly increase the levels of hepatic enzymes (ALT, AST, ALP, and GGT) and renal enzymes (creatinine and BUN). Additionally, histopathological findings of liver and kidney cross-sections showed observable histological changes in each case. Thus, the study findings confirm the idea that the use of saffron petal hydroalcoholic extract can affect the renal and hepatic cells and cause serious damages to them. The changes might have come about due to the direct effect and/or the body organs' hypoxia. It is worth mentioning that despite the use of three non-toxic dosages, namely $30 \%, 60 \%$, and $90 \%$ of $\mathrm{LD}_{50}$ dosage, of this extract, i.e. 200,400 , 
and $600 \mathrm{mg} / \mathrm{kg}$, the damage to these dosages (especially to the hepatic tissue and their effects on the increase in kidney and liver functional parameters) were found to be still persistent in the long run. Therefore, in the case of using this extract for taking advantage of its positive and therapeutic effects, dosages a lot lower than $\mathrm{LD}_{50}$ should be applied carefully.

\section{ABBREVIATIONS}

HAESP: Hydroalcoholic extract of saffron petal

LD: Lethal Dosage

ALP: Alkaline phosphatase

AST: Aspartate aminotransferase

ALT: Alanine aminotransferase

GGT: Gamma-glutamyl transferase

BUN: Blood urea nitrogen

H\&E: Hematoxylin-Eosin

Cr: Creatinine

TG: Triglyceride

Chol: Cholesterol

CPK: Creatine phosphokinase

\section{ACKNOWLEDGMENTS}

The authors of the present study would like to express their gratitude to the research and technology deputy ship of Ilam University of Medical Sciences, and Qaem Laboratory.

\section{AUTHOR'S CONTRIBUTIONS}

Monireh Azizi, Mojtaba Mohamadpour and Mansour Amraei Conceived and designed the experiments, Monireh Azizi, Mohammad Reza Hafezi Ahmadi, Mojtaba Mohamadpour and Sirous Asadi preparation and article reviewing, Monireh Azizi, Sirous Asadi, Ehsan Shirzadpour and Mansour Amraei: performed the experiments, Monireh Azizi, Mohammad Reza Hafezi Ahmadi and Ehsan Shirzadpour interpretation and drafting article and revising it critically, Mohammad Reza Hafezi Ahmadi, Ehsan Shirzadpour and Mansour Amraei analyzed and interpreted the data, Ahmad Daemi: contributed reagents, materials, analysis tools or data, Mansour Amraei wrote the paper. All authors read and approved the manuscript.

\section{FUNDING}

Not applicable.

\section{AVAILABILITY OF DATA AND MATERIALS}

Data and materials used and/or analyzed during the current study are available from the corresponding author on reasonable request.

\section{ETHICS APPROVAL AND CONSENT TO PARTICIPATE}

Not applicable.

\section{CONSENT FOR PUBLICATION}

Not applicable.

\section{COMPETING INTERESTS}

The authors declare that they have no competing interests.

\section{REFERENCES}

1. Leonti M, Verpoorte R. Traditional Mediterranean and European herbal medicines. Journal of Ethnopharmacology. 2017;199:161-167. PMID: 28179113. Available from: https: //doi.org/10.1016/j.jep.2017.01.052.

2. Sadeghi Z, Akaberi M, Sobhkhizi A, Sahebkar A, Emami SA. Evaluation the ethno-pharmacological studies in Iran during 2004-2016: A systematic review. Journal of Cellular Physiology. 2018;233:914-923. PMID: 28092098. Available from: https://doi.org/10.1002/jcp.25803.

3. Christodoulou E, Kadoglou NP, Kostomitsopoulos N, Valsami G. Saffron: a natural product with potential pharmaceutical applications. Journal of Pharmacy and Pharmacology. 2015;67:1634-1649. PMID: 26272123. Available from: https: //doi.org/10.1111/jphp.12456.

4. Xue XH. Cultivation of Crocus sativus. Zhong Yao Tong Bao. 1982;7:3-4.

5. Kafi M, Husaini AM, Ozturk M, Altay V. An Expensive Spice Saffron (Crocus sativus L.): A Case Study from Kashmir, Iran, and Turkey. Global Perspectives on Underutilized Crops. 2018;p. 109-149. Available from: https://doi.org/10.1007/978-3-31977776-4_4.

6. Javadi B, Sahebkar A, Emami A. A Survey on Saffron in Major Islamic Traditional Medicine Books. Iranian Journal Basic Medical Sciences. 2013;16:1-11.

7. Winterhalter $P$, Straubinger M. Saffron-renewed interest in an ancient spice. Food Reviews International. 2000;16:39-59. Available from: https://doi.org/10.1081/FRI- 100100281.

8. Rahmani AH, Khan AA, Aldebasi YH. Saffron (Crocus sativus) and its Active Ingredients: Role in the Prevention and Treatment of Disease. Pharmacognosy Journal. 2017;9:873-879. Available from: https://doi.org/10.5530/pj.2017.6.137.

9. Rameshrad M, Razavi BM, Hosseinzadeh H. Saffron and its derivatives, crocin, crocetin and safranal: a patent review. Expert Opinion on Therapeutic Patents. 2018;28:147-165. PMID: 28705037. Available from: https://doi.org/10.1080/13543776. 2017.1355909.

10. Gonda S, Parizsa P, Surányi G, Gyémánt G, Vasas G. Quantification of main bioactive metabolites from saffron (Crocus sativus) stigmas by a micellar electrokinetic chromatographic (MEKC) method. Journal of Pharmaceutical and Biomedical Analaysis. 2012;66:68-74. PMID: 22464563. Available from: https://doi.org/10.1016/j.jpba.2012.03.002.

11. Moras B, Loffredo L, Rey S. Quality assessment of saffron (Crocus sativus L.) extracts via UHPLC-DAD-MS analysis and detection of adulteration using gardenia fruit extract (Gardenia jasminoides Ellis). Food Chemistry. 2018;257:325-332. PMID: 29622218. Available from: https://doi.org/10.1016/j.foodchem. 2018.03.025.

12. Rahaiee S, Moini S, Hashemi M, Shojaosadati SA. Evaluation of antioxidant activities of bioactive compounds and various extracts obtained from saffron (Crocus sativus L.): a review. Journal of Food Science and Technology. 2015;52:18811888. PMID: 25829569. Available from: https://doi.org/10. 1007/s13197-013-1238-x. 
13. Jiang Z, Gu M, Liu J, Li H, Peng J, Zhang Y. Anticancer activity of crocin against cervical carcinoma (HeLa cells): Bioassessment and toxicity evaluation of crocin in male albino rats. Journal of Photochemistry and Photobiology B: Biology. 2018;180:118124. PMID: 29413694. Available from: https://doi.org/10.1016/ j.jphotobiol.2018.01.013.

14. Shafiee M, Arekhi S, Omranzadeh A, Sahebkar A. Saffron in the treatment of depression, anxiety and other mental disorders: Current evidence and potential mechanisms of action. Journal of Affective Disorders. 2018;227:330-337. PMID: 29136602. Available from: https://doi.org/10.1016/j.jad.2017. 11.020 .

15. Hatziagapiou K, Lambrou Gl. The Protective Role of Crocus Sativus L. (Saffron) Against Ischemia- Reperfusion Injury, Hyperlipidemia and Atherosclerosis: Nature Opposing Cardiovascular Diseases. Current Cardiology Reviews. 2018;14:272289. PMID: 29952263. Available from: https://doi.org/10.2174/ $1573403 X 14666180628095918$.

16. Leone S, Recinella L, Chiavaroli A, Orlando G, Ferrante C, Leporini $L$, et al. Phytotherapic use of the Crocus sativus L. (Saffron) and its potential applications: A brief overview. Phytotherapy Research. 2018;32:2364-2375. PMID: 30136324. Available from: https://doi.org/10.1002/ptr.6181.

17. Hariri AT, Moallem SA, Mahmoudi M, Memar B, Razavi BM, Hosseinzadeh $\mathrm{H}$. Effect of Crocus sativus L. stigma (saffron) against subacute effect of diazinon: histopathological, hematological, biochemical and genotoxicity evaluations in rats. J Pharmacopuncture. 2018;21:61-69.

18. Najafi H, Mahmoudzadeh L, Shakibaei D. Protective effects of Saffron hydroalcoholic extract against renal tissue damages induced by ischemia-reperfusion in rats. Journal of Kermanshah University Medical Sciences. 2014;18:138-146.

19. Bukhari Sl, Manzoor M, Dhar MK. A comprehensive review of the pharmacological potential of Crocus sativus and its bioactive apocarotenoids. Biomedicine and Pharmacotherapy. 2018;98:733-745. PMID: 29306211. Available from: https: //doi.org/10.1016/j.biopha.2017.12.090.

20. Nasri $H$, Shirzad H. Toxicity and safety of medicinal plants. Journal of HerbMed Plarmacology. 2013;2:21-22.

21. Hosseinzadeh $H$, Shariaty MV, Sameni AK, Vahabzadeh $M$. Acute and sub-acute toxicity of crocin, a constituent of Crocus sativus L. (saffron), in mice and rats. Pharmacologyonline. 2010;2:943-951.

22. Schmidt M, Betti G, Hensel A. Saffron in phytotherapy: Pharmacology and clinical uses. Wiener Medizinische Wochenschrift. 2007;157:315-319. PMID: 17704979. Available from: https://doi.org/10.1007/s10354-007-0428-4.

23. Modaghegh $\mathrm{MH}$, Shahabian M, Esmaeili H, Rajbai O, Hosseinzade $\mathrm{H}$. Safety evaluation of saffron (Crocus sativus) tablets in healthy volunteers. Phytomedicine. 2008;15:1032-1037. PMID: 18693099. Available from: https://doi.org/10.1016/j. phymed.2008.06.003.

24. Khleifat K, Shakhanbeh J, Tarawneh K. The chronic effects of Teucrium polium on some blood parameters and histopathology of liver and kidney in the rat. Turkish Journal of Biology. 2002;26:65-71.

25. Sitta KHA, Shomah MS, Salhab AS. Hepatotoxicity of Teucrium polium L tea: supporting evidence in mice models. Australian. Journal of Herbal Medicine. 2009;21(4):106-108.
26. Krache I, Boussoualim N, Charef N, Trabsa H, Ouhida S, Benbacha F, et al. Evaluation of acute and chronic toxic effects of Algerian germander in Swiss albino mice. Journal of Applied Pharmaceutical Scienc. 2015;5:027-032.

27. Amraei M, Ghorbani A, Seifinejad Y, Mousavi SF, Mohamadpour M, Shirzadpour E. The effect of hydroalcoholic extract of Teucrium polium L. on the inflammatory markers and lipid profile in hypercholesterolemic rats. Journal of Inflammation Research. 2018;11:265-272. PMID: 29950880. Available from: https://doi.org/10.2147/JIR.S165172.

28. Loomis T. Essential of Toxicology. 3rd ed. Lea and Febiger. Philladelphia. 1986; p. 67-78.

29. Kennedy GL, Ferenz RL, Burgess BA. Estimation of acute oral toxicity in rats by determination of the approximate lethal dose rather than the LD50. Journal of Applied Toxicology. 1986;6:145-148. PMID: 3722708. Available from: https://doi org/10.1002/jat.2550060302.

30. Bahmani M, Rafieian M, Baradaran A, Rafieian S, Rafieiankopaei M. Nephrotoxicity and hepatotoxicity evaluation of Crocus sativus stigmas in neonates of nursing mice. Journal of Nephropathology. 2014;3:81-85.

31. Babaei A, Arshami J, Haghparast AR, Mesgaran MD. Effects of Crocus sativus petals extract on biochemical blood parameters in male rats. Arak Medical University Journal (AMUJ). 2013;16:14-21.

32. Karimi G, Taiebi N, Hosseinzadeh $\mathrm{H}$, Shirzad F. Evaluation of subacute toxicity of aqueous extract of Crocus sativus L. stigma and petal in rats. Journal of Medicinal Plants. 2004;4:29-35.

33. Karimi G, Hosseinzadeh $H$, Khaleghpanah P. Study of antidepressant effect of aqueous and ethanolic extracts of Crocus sativus in mice. Iranian Journal of Basic Medical Sciences. 2001;4:11-15.

34. Nair SC, Kurumboor SK, Hasegawa JH. Saffron chemoprevention in biology and medicine: A review. Cancer Biotherapy. 1995;10:257-264. PMID: 8590890. Available from: https: //doi.org/10.1089/cbr.1995.10.257.

35. Stockham SL, Scott MA. Fundamentals of veterinary clinical pathology. Blackwell Publishing, Ames, lowa, USA. 2002;p. 434-459.

36. Contreras-Zentella ML, Hernández-Muñoz R. Is Liver Enzyme Release Really Associated with Cell Necrosis Induced by Oxidant Stress? Oxidative Medicine and Cellular Longevity. 2016;PMID: 26798419. Available from: https://doi.org/10. $1155 / 2016 / 3529149$.

37. Sherlock S, Dooley J. Drugs and the liver. In: Diseases of the liver and biliary system. 10th ed. Oxford. Blackwell Science. 1997;p. 337-369.

38. Curtis D, Klaassen PD. Casarett and Doull's Toxicology: The Basic Science of Poison. 7th ed. NewYork: McGraw-Hill Press. 2008;p. 557.

39. Wang CJ, Hwang LS, Lin JK. Reversible hepatic black pigmentation and enzyme alteration induced by prolonged feeding of high dose of crocin dyes in rats. Proceedings of the National Science Council Republic of China: Part B. 1984;8:246-253.

40. Piyachaturawat $P$, Tubtim $C$, Chuncharunee $A$, Komaratat $P_{i}$ Suksamrarn A. Evaluation of the acute and subacute toxicity of a choleretic phloracetophenone in experimental animals. Toxicology Letters. 2002;129:123-132. Available from: https://doi.org/10.1016/S0378-4274(02)00006-1. 